\title{
An Analysis of China's Economic Downturn----From the Perspective of Neoclassical Economics
}

\author{
Zihao Chen \\ Stiftung Louisenlund, Germany. \\ zihao1600@outlook.com
}

Keywords: Economic downturn; neoclassical economics; Solow model.

\begin{abstract}
Since the financial crisis in 2008, China's economic growth has reached a turning point and there exists increasing pressure in China's economy due to its downward trend. From the perspective of neoclassical economics, and with the aid of Solow production function, this paper makes a comparison between the period of China's rapid economic growth and that of low speed growth, in an attempt to analyze the cause of the current economic downturn in China. The results indicate that the causes of the current economic downturn in China lie in the decline in capital remuneration, the disappearance of demographic dividend and the slow economic transition.
\end{abstract}

\section{Introduction}

From 1978 to 2007, the actual China's annual GDP growth rate reached to $9.8 \%$. As a low-income developing country with a weak economic base, it is obviously a miracle for China to achieve this rare high-speed growth in the context of the world economy's generally sluggish growth. However, since the international financial crisis in 2008, the global economy has entered a low-speed growth state, and the Chinese economy has not been spared. The economic growth rate in China has dropped significantly (figure 1). According to the data, China's GDP growth began to face a pressure of going downward in 2010, and there is certain inertia of China's economic downturn. It gradually declined from $10.5 \%$ in 2010 to $7 \%$ in the first quarter of 2015 (figure 1). According to the theory of Samuelson's multiplier acceleration, the investment, income, and consumption in economic society will exert a mutual influence as well as a mutual adjustment on each other. With the accelerating number, the rising income and consumption will bring about new investment. Meanwhile, through the multiplier, further investment will in turn bring about a growth in income, thus form a phenomenon of cumulative economic expansion or contraction. Therefore, if the government doesn't intervene with economy, and make various departments, regions, and each link of social production influence each other, China's economic growth will further slow down, which will continue to intensify the pressure on the economic downturn. On the basis of realizing the general rules of economic growth, it is a key point to judge the stage of economic growth, and to reveal the economic growth pattern of a specific period, especially to reveal those characteristics with a turning-point meaning, so as to understand the process of economic growth, and form a key policy thought with direction and pertinence.

On the basis of summarizing the rule of the economic growth in China, this paper is trying to make an empirical analysis of the situation of China's economy both in the years before 2008 and in the years after 2008, with the year 2008 as a turning point. By making a comparison between the situation in the period of China's rapid economic growth and that in low speed growth period, the paper concludes the essential cause of China's economic downturn. 


\section{The GDP Growth Rate In China Mainland}

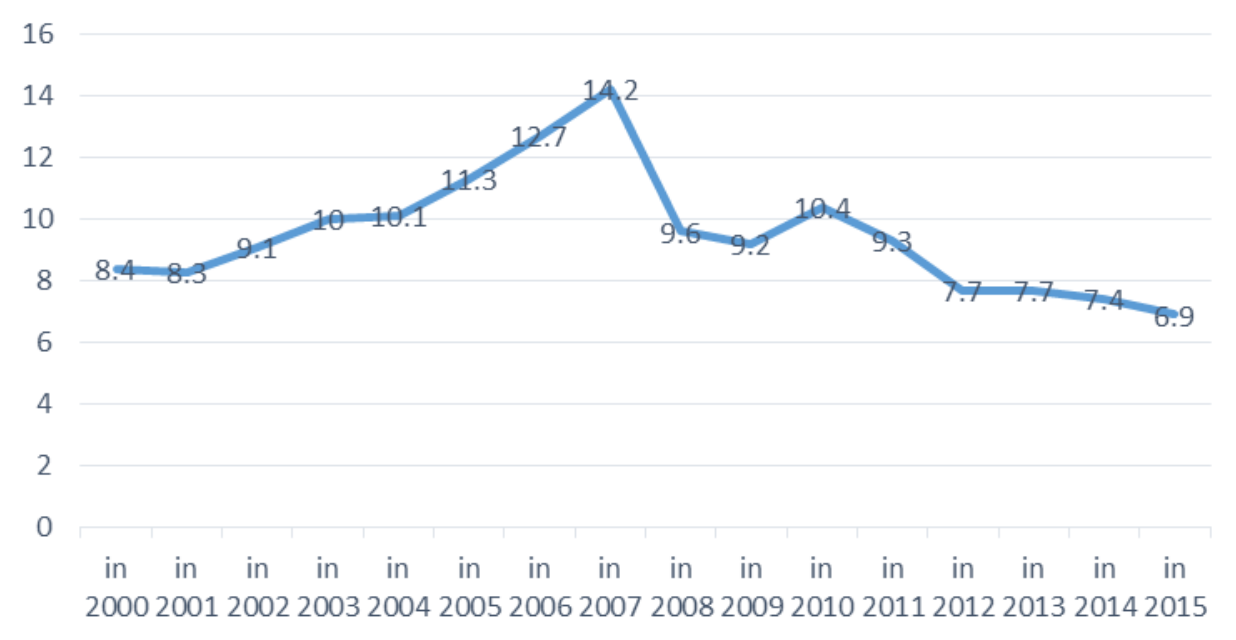

Fig. 1 the GDP Growth Rate in China Mainland from 2000 To 2015

\section{Literature Review of the Theories of Economic Growth}

In his historic masterpiece The Wealth of Nations, the classical economist Adam Smith (1776) for the first time systematically probes into the ways to achieve economic growth as fast as possible, and he also systematically demonstrates the positive role that the market economy with free competition played on the growth of modern economy(Adam Smith 2013). He believes that the main way to increase national wealth and promote economic growth is to increase the number of workers, increase capital input, strengthen the division of labor and improve machinery so as to increase productivity. He also notes that all the above factors can be achieved by the market itself without the intervention of the state. Since then, economic growth and the theory of economic growth have become one of the core subjects of the research on economics. Actually, the constant development of economic growth theory is exactly the process that economists constantly seek and explain the source of economic growth. The representative views are "the theory of capital determinism", "the theory of technological progress", "the theory of human resources capital" and "the theory of labor division-specialization".

\subsection{The Theory of Capital Determinism.}

"Capital determinism" believes that production inputs are made up of natural conditions, labors and material capital. Among that, the supply of natural resources will affect economic growth, but it cannot play a decisive role in economic growth. The supply of labour in developing countries is quite abundant and will not retrain economic growth. What is very scarce in developing countries is just material capital, however, material capital is a necessary condition for economic growth. Therefore, the formation of material capital and whether it is abundant or not are the decisive factors in economic growth.The main representatives of this view are the Harrod-Domar model and two-gap model built by Harrod in 1939 and Domar in 1948.

The Harold - Domar model is based on Keynes's income determinism, and it dynamizes Keynes' theory and makes it in a long-term, so as to deduce the expression of $\mathrm{G}=\mathrm{S} / \mathrm{C}$. In the expression of $\mathrm{G}=\mathrm{S}$ $/ \mathrm{C}, \mathrm{G}$ refers to the growth rate of $\mathrm{G} \mathrm{N} \mathrm{P,S} \mathrm{refers} \mathrm{to} \mathrm{the} \mathrm{saving} \mathrm{rate,} \mathrm{namely} \mathrm{the} \mathrm{capital} \mathrm{accumulation}$ rate, $\mathrm{C}$ refers to the capital coefficient, namely the ratio of capital and output; The growth rate of $\mathrm{G} \mathrm{N}$ $\mathrm{P}$ is proportional to the savings rate and inversely proportional to the capital coefficient. Supposing that capital coefficient $\mathrm{C}$ remains the same, if we want to make the economy grow constantly, we must constantly cut out a certain part from G N P for savings, and transfer them into investment, so that the constant capital formation become the decisive factor for sustained economic growth. The two-gap model is based on the Keynesian macro analysis, and according to this model, the saving gap and foreign exchange gap must be adjusted. Outside the gap, it is necessary to seek additional capital in 
order to make the two gaps equal. Thus the model demonstrates capital's decisive effect on economic growth.

\subsection{The Theory of Technological Progress.}

According to "the theory of technological progress", technological progress is the key factor that determines the level of economic growth in the case that the input of factor resources is certain and the resource allocation is in the Pareto optimal state. The typical representatives of this view are Solow, $\mathrm{K}$. Arrow and Roomer. P. M.. The neoclassical economist Solow established the production function $\mathrm{Y}=\mathrm{A} \mathrm{f}$, among which "Y" refers to the output of the economic system, "A" represents the technical level, and "f" refers to the efficiency of resource allocation. Neoclassical economists believe that product and factor markets will always remain balanced, no matter from the view of producers or from that of consumers, there always exists long-term efficient allocation of resources, namely the Pareto optimal state. Therefore, in their view, the level of economic growth is determined by the technical factor A. Later, Denison and other economists proposed the concept of "residual value", which also supported this view. What needs to be pointed out is that the technical progress in the Solow model is defined exogenously. Therefore, the author names Solow model as "the theory of exogenous technological progress".

K. Arrow and Paul Romer broke the assumptive precondition of Solow model, endogenized the role of technological progress in economic growth, and deepen people's understanding of the positive role of technological progress. In addition, it realized the transference from "theory of exogenous technological progress" to "theory of endogenous technological progress". In 1962, the Nobel Prize winner Arrow proposed the "learning by doing" model (Arrow and Hurwicz 1962). He believed that technological progress was the intrinsic factor of economic growth model and assumed that the scale yield would not change. At the same time, capital input increased knowledge output, and overall, the economic scale gradually increased. The representative figure of new economic growth theory Paul Romer based on his two theses in 1986 and 1986, endogenized the technological reformation, and set up a long-term growth model of endogenous technological reformation (Romer 1986, Romer, 1990). In the model of endogenous technological reformation, Romer points out that technical knowledge can not only form its own increasing returns, but also can make the elements such as capital and labor inputs to produce increasing returns, so as to realize the increasing scale effect of economic growth. At the same time, the accumulated knowledge will naturally have external effects, and the spillover of technology will greatly promote technological change, thus increasing effect of the scale of economic growth. Therefore, Romer believes that technological change is the result of knowledge accumulation, which makes technological change the motive power of long-term economic growth.

\subsection{The Theory of Human Resources Capital.}

"The theory of human resources capital emphasizes the important role of intellectual resources in the economic growth. It believes that human resources capital is the main source of economic growth. The typical representatives of this view are Schultz and Lucas. American economist Schultz divides capital into material capital and human resources capital. And he believes that through the investment in education, sanitation and other aspects, with the general human resources being transferred into high quality human capital (including physical strength, intelligence, skills, etc.), the "effect of knowledge" and "the effect of non-knowledge "can be produced, hence it helps promote economic growth. Moreover, human resources capital can generate incremental benefits, which can reverse the trend of diminishing marginal returns of capital and labor factors. So Mr Schultz argues that human capital is a guarantee of steady economic growth (Schultz, 1961). Lucas, the representative person of new economic growth theory, by analyzing two-capital model and two-product model, includes human capital as an independent factor into the economic growth model. He utilizes more microscopic method to specify Schultz's human capital concept and Solow's technological progress concept into "everyone's", "specialized" human capital, and puts forward the economic growth mode with human capital as the core. Lucas points out that there are both internal effects and external effects of human capital investment. The so-called internal effect refers to the contribution of human capital to the productivity of investors. While the external effect refers to the spillover effect of human 
knowledge improvement. He believes the level of people's human capital (knowledge, skills,) can be passed from one to another, which, as a result, can not only improve the productivity of the workers, but also improve the productivity of material capital; it can not only improve the productivity of enterprise and department themselves who invest human capitals, but also may lead to the improvement of the productivity of other enterprises or departments, thus it helps form an increasing benefits effect of the scale of production. At the same time, Lucas's growth model suggests that countries with large human capital will achieve a more sustained and rapid economic growth(Lucas Jr 1988). So, in his view, human capital is also an "engine of economic growth".

\subsection{The Theory of Labor Division_-Specialization.}

According to "the theory of labor division__ specialization", the division of labor is the source of economic growth, the idea of which can be traced back to Adam Smith. Allyn Young deepens and develops Smith's idea. Yang believes that Smith only investigated one form of the division of labor, but there are other forms of it. One of the most important form of the division of labor is the increase of the roundabout degree of production. That is to say, there appear new intermediate products in economy, and the chain between their initial investment and their final output was lengthened. (Young 1928) Therefore, there are two views on the division of labor: (1) the division of labor means the diversification of economy, and the division of labor is manifested in the emergence of new industries and the strengthening of the roundabout degree of production, and that economy with the division of labor is a diversified economy.(2) the division of labor indicates that workers devote more and more time to the production of one certain product, that is to say, there is a deepening of the degree of specialization of workers, and economy with the division of labor is a specialized economy.(Young, 1928). After the 1980s, from different aspects, Becker and Murphy, Yang Xiaokai and Borland respectively put forward the economic growth model which indigenized the degree and structure of the division of labor and specialization. They not only put forward a method to quantitatively measure the degree of specialization, but also analyzed and illustrated how the degree and structure of the division of labor and specialization is determined, by using the quantified model. They illustrated how the changes of division of labor and specialization will have an impact on economic growth. Becker and other economists inherited and developed Smith's ideas. They regard the division of labor as equal to specialization, and proposed the Becker-Murphy model (Becker and Murphy 1992). According to the result of their model, what determines the level of the division of labor mainly lies in the combination of workers with required coordination costs and social knowledge level? The coordination cost will be decreased with increasing social stock of knowledge, while the evolution of labor division and knowledge accumulation will promote each other. They two together determine the economic growth. According to Yang Xiaokai-Borland economic growth model, the economy will evolve from self-sufficiency to the division of labor due to the existence of specialized interests. Besides, because of the existence of transaction costs, people an optimal decision in the level of specialization. All the people's decisions in the level of specialization together determines the level of the current division of labor, and the level of labor division determines the rate of economic growth. As long as the division of labor evolves to a certain level and maintains the potential of further division of labor, the per capita income will increase with time, thus the sustainable economic growth is possible. Therefore, even in the circumstance of an constantly increasing population growth, the economy is likely to grow constantly as long as the potential for further division of labour is maintained. If the number of population increases, more strictly speaking, if the number of people entering the trade increases, the potential of division of labor will be further improved, thus ensuring the continuous improvement of the growth rate.(Yang and Borland 1991).

\section{The Analysis of the Factors of China's Economic Growth}

The model of China's economic growth is one of the hot issues in domestic economic circles in recent years. Many studies attempt to use the method of total factor productivity (TFP) to analyse the source of economic growth in China, in order to judge the sustainability of China's existing economic 
growth mode. Some put forward the reform proposals of the future economic growth mode about the current economic development model. There are two major kinds of views, one holds that economic growth has a periodic law, investment to economic growth at the present stage is a stage of economic development, and we should not talk about the sustainability of economic development beyond this stage. The other view holds that we must transform the way of economic growth in the process of China's economic growth, and there might appear a series of problems with investment as the drive of economic growth. Within the framework of the neoclassical economic growth theory, from the labor capital and TFP's contribution to China's economic growth, this paper will explore the necessity and the specific measures of the methods of the transformation of the economic growth in China.

\subsection{The Supply of Labor under the Dual Economic Structure.}

As a typical country with dual economy, in China, there are much gap between the developing levels of urban areas centered modern departments and that of rural areas centered traditional departments. There are till evident signs of segmentation between the urban areas and the rural areas, as well as the segmentation between some regions. China's economy has experienced tremendous fluctuations despite the rapid growth due to its severe lack of micro-mechanism and inefficient allocation of resources. During the period of the reform and opening up, according to Lin If's theory of comparative advantage, China made full use of the advantage of the enormous Chinese labors, developed labor-intensive industries, absorbed a large number of surplus labor force, and promoted the transference of the labor force. This method, on the one hand, ensured the labor supply in the process of the economic growth. On the other hand, it increased the capital accumulation, the demographic dividend formed through that was released by the mechanism of the reform of the resource allocation. Besides, the demographic dividend was realized by the process of participating in economic globalization, which as a result delayed the process of the diminish in capital returns. The comparative advantage of resources reflected in the quality and price of labors in China displayed full its role through the competitive status of labor-intensive products in the international market, and the international labor market made China's rich labor resources be effectively allocated.

\subsection{The Formation of Capital and the Growth of Economy.}

Because investment is one of the three components of GDP, the moderate expansion of investment has certain pulling and driving effect on the growth of GDP. This effect is achieved by expanding production capacity in order to enhance the impetus on GDP and by expanding the investment demand, the corresponding increase of demand will bring about driving force to GDP. (Rostow, 1962). Seen from the aspect of demand, the expansion of investment scale can lead to an increase in demand for investment products, thus resulting in an increase in employment and income, which leads to an increase in the demand for consumer goods. Seen from the aspect of supply, investment is beneficial to the expansion and reproduction in the future, and helps to increase the supply of social products. Therefore, it is necessary to have a certain amount of investment to ensure the speed of development of the national economy. It is not difficult for us to see why investment plays an important role in boosting GDP growth. Investment has been the dominant factor in the process of China's economic growth, and capital formation has contributed most to China's economic growth. According to existing data, capital's contribution to China's economic growth has been stable at about $56.2 \%$ between 1978 and 2008. It is worth noting that the investment is a "double-edged sword" for the development of the national economy. If we expand investment blindly beyond the national financial and material resources, it also will hinder the healthy and orderly development of national economy. In the process of the industrialization of a country, the contribution of investment to national economy is a development process.

\subsection{Total Factor Productivity and the Factors of Its Change.}

Total factor productivity (TFP) refers to "the efficiency of production activities within a certain period of time", that is the developing and utilizing efficiency whose resources include manpower, material resources and financial resources. It reflects the part that cannot be explained by the input of production factors in the growth of output, including the improvement of micro-technical efficiency and the improvement of the efficiency of resource allocation. More and more researches suggest that 
physical capital and intangible capital cannot explain the enormous income differences between the countries today, the importance of the saving rate is also limited, and only total factor productivity (TFP) is the most important. To understand the big difference in income between countries, there must be a model of the growth of total factor productivity(1998), Prescott (Easterly and Levine, 2001). Zheng Jinghai (in 2008) pointed out that although there appeared a large divergence in the measure of total factor productivity, through the analysis of existing materials, China's economic growth in recent years was promoted more and more by investment, and the extensive economic growth mode will stop the sustainability of China's economic growth .

\section{Empirical Analysis of China's Economic Growth Based on Theories of Neoclassical Economics}

To sum up, according to the actual situation of China's economy, the most practical theory is still the neoclassical theory to explore the law of economic operation in China. The rest of this paper will employ the Solow model, to study of the situation of China's economic operation since 2000. With the year 2008 as the turning point, by comparing the economic operation situation before and after 2008, this paper will explore the essential cause of China's economic downturn after 2008.

\subsection{Introduction of Models.}

The American economist Solow started the theory of the source of economic growth. He proposed the Solow economic growth model in his paper "Technical Change and The Aggregate Production Function" (Solow 1957). Solow pointed out that in the circulation process of expansion and reproduction in economic society, the origins that determine the yearly growth in national income can be divided into three types: the increasing labor input, increasing capital input and the improvement of production efficiency of the two factors caused by technology progress.

Therefore, supposing the social production function is Cobb-Douglas production function, then the Solow production model is set as follows:

$$
\mathrm{Y}=\mathrm{f}(\mathrm{K}, \mathrm{L})=\mathrm{A}_{\mathrm{t}} \mathrm{K}^{\alpha} \mathrm{L}^{\beta}
$$

Y represents social production, a represents technical level, $\mathrm{K}$ represents the social capital stock, $\mathrm{L}$ represents the Labor force, $\alpha$ and $\beta$ respectively represent the elasticity of capital output and the elasticity of labor output, while the variable $t$ represents the time. If $\alpha+\beta=1$, it means that the production function is the first order homogeneous function, and the scale compensation remains the same. If $\alpha+\beta>1$, it means the increment of scale returns. If $\alpha+\beta<1$, it means a diminishing of scale returns.

\subsection{Data Collation and Index.}

\subsubsection{Index of Social Output.}

There are many indexes represent output. Considering the convenience and authority of data acquisition, the paper adopts the gross domestic product (GDP) as the index of total output in the whole society. In addition, the expression of data sources is demonstrated based on current year's prices. Considering the changes of monetary purchasing power since 1978 in our country, the paper adopted the GDP figures released by China Statistical Yearbook to calculate the actual GDP with in 2000 as a benchmark.

\subsubsection{Index of Capital Stock.}

The paper adopted each year's gross capital formation as the capital stock index. Also taking into account the change in price, each year's gross capital formation is divided by the GDP deflator, and the total amount of real capital formation will come into being.

The price deflator is equal to the current year's nominal GDP/ The current year's actual GDP.

\subsubsection{Index of Labor Input.}

In terms of labor input index, the paper adopted China's employment number from 2001 to 2015 as a measure. China Statistical Yearbook published the number of the employed people at the end of each year. Taking into account the uneven nature of the data, the paper adopted the following method: 
The number of employed people in this year $=($ the number of workers at the beginning of this year + the number of people working at the end of this year) $/ 2$. The number of workers at the beginning of this year is equal to the number of workers at the end of last year.

\subsection{Fitting of Models.}

The form of Cobb-Douglas production function is in the form of power function. Before fitting the model of the nonlinear function, we should first of all transfer the nonlinear function into a linear form by taking the logarithm of both sides of the production function. take logarithm on both sides of. Take the logarithm of both sides of equation (1):

$$
\mathrm{LnY}=\mathrm{LnA}+\alpha \mathrm{LnK}+\beta \mathrm{LnL}
$$

At the same time, considering the continuity of macro economic operation, this model increases the lag term of interpreted variables, namely:

$\mathrm{LnY}=\mathrm{LnY}_{\mathrm{t}-1}+\mathrm{LnA}+\alpha \mathrm{LnK}+\beta \mathrm{LnL}$

This paper adopted the software STATA to fit the macroeconomic data in China from 2000 to 2007, and got the following results:

\begin{tabular}{|c|c|c|}
\hline & $\begin{array}{c}2001-2007 \\
\operatorname{lnG}\end{array}$ & $\begin{array}{c}2008-2015 \\
\operatorname{lnG}\end{array}$ \\
\hline L.InG & $\begin{array}{c}0.889^{* * *} \\
(7.91)\end{array}$ & $\begin{array}{c}-0.318^{*} \\
(-0.81)\end{array}$ \\
\hline $\ln K$ & $\begin{array}{l}0.657^{*} \\
(3.04)\end{array}$ & $\begin{array}{l}0.270^{*} \\
(2.27)\end{array}$ \\
\hline $\operatorname{lnL}$ & $\begin{array}{c}-9.260^{*} \\
(-2.44)\end{array}$ & $\begin{array}{c}34.70^{*} \\
(2.69)\end{array}$ \\
\hline _cons & $\begin{array}{c}98.12^{*} \\
(2.43) \\
\end{array}$ & $\begin{array}{c}-376.4^{*} \\
(-2.69) \\
\end{array}$ \\
\hline $\begin{array}{c}N \\
\text { Adj- } R^{2}\end{array}$ & $\begin{array}{c}7 \\
0.9988\end{array}$ & $\begin{array}{c}8 \\
0.9940\end{array}$ \\
\hline
\end{tabular}

The numbers in parentheses represent the value of " $\mathrm{t}$ ". The symbols *, ** and *** respectively mean that the value of " $t$ " is remarkable at the level of $10 \%, 5 \%$ and $1 \%$ respectively. $N$ refers to the number of sample observations. Adj-R2 refers to the adjustment of the measurement model. It can be seen from the measurement results that the value of R2 is greater than $99 \%$, and the lag term of the explanatory variable of the t-value in model 3 is significant at the significance level of $10 \%$.

\subsection{Each Factor's Contribution to China's Economic Growth From 2001 to 2015.}

According to the results of model 4.3, this paper calculates each factor's contribution to China's economic growth respectively from 2001 to 2007 and from 2008 to 2015 . The economic contribution of total factor productivity "a" is the sum of what economic growth rate minus the contribution of capital and labor to economic growth.

Table 1 Each Factor's Contribution to China's Economic Growth

\begin{tabular}{|c|c|c|c|c|c|c|}
\hline Year & $\mathrm{y}$ & $\mathrm{k}$ & 1 & $\alpha^{*} \mathrm{k}$ & $\beta^{* 1}$ & $\mathrm{a}$ \\
\hline 2001 & 8.3 & 9.31 & 1.30 & 6.12 & -12.08 & 14.26 \\
\hline 2002 & 9.1 & 14.88 & 0.98 & 9.78 & -9.07 & 8.39 \\
\hline 2003 & 10 & 19.50 & 0.94 & 12.81 & -8.69 & 5.88 \\
\hline 2004 & 10.1 & 13.85 & 1.03 & 9.10 & -9.55 & 10.56 \\
\hline 2005 & 11.3 & 9.70 & 0.83 & 6.37 & -7.70 & 12.62 \\
\hline 2006 & 12.7 & 14.14 & 0.76 & 9.29 & -7.02 & 10.43 \\
\hline 2007 & 14.2 & 9.80 & 0.77 & 6.44 & -7.15 & 14.91 \\
\hline 2008 & 9.6 & 14.34 & -1.85 & 3.87 & -10.27 & 15.73 \\
\hline 2009 & 9.2 & 23.07 & 0.35 & 6.23 & 12.12 & -9.15 \\
\hline 2010 & 10.4 & 9.90 & 0.37 & 2.67 & 12.68 & -4.95 \\
\hline 2011 & 9.3 & 7.67 & 0.41 & 2.07 & 14.36 & -7.13 \\
\hline 2012 & 7.7 & 10.70 & 0.37 & 2.89 & 12.90 & -8.08 \\
\hline 2013 & 7.7 & 10.91 & 0.36 & 2.95 & 12.35 & -7.60 \\
\hline 2014 & 7.4 & 4.79 & 0.36 & 1.29 & 12.44 & -6.33 \\
\hline 2015 & 6.9 & -4.68 & 0.26 & -1.26 & 8.89 & -0.73 \\
\hline
\end{tabular}




\subsection{Analysis of Empirical Results.}

As can be seen from the lag terms of the two stages' models, there is a significant upward trend in China's economy from 2001 to 2007. While from 2008 to 2015, there is an obvious downward trend. So we can conclude that, after the global financial crisis in 2008, although China's economy experienced the fiscal stimulus of RMB "four trillion" Yuan and there was a significant rebound in China's economy, on the whole, the downward trend of China's economy is quite obvious after 2008.

In terms of the capital changes in the two phases, the capital elasticity decreased from 0.657 before 2008 to 0.27 after 2008. Comprehensively seen from table 1, it is clear that the contribution of capital accumulation to China's economic growth is shrinking. According to neoclassical theory, this is exactly the phenomenon of diminishing marginal returns of capital. However, it is worth noting that the elasticity of capital has fallen by more than 50\% from 2008 to 2015, and that such a sharp decline cannot be explained only by the diminishing marginal utility of capital. With a further observation on the economic contribution of capital proportion in table 1, it can be seen that the large range of decline started in 2010, which means that although our country's "four trillion" policy implemented at that time has promoted the economic recovery in a short time, this kind of fiscal stimulus are inefficient and unsustainable.

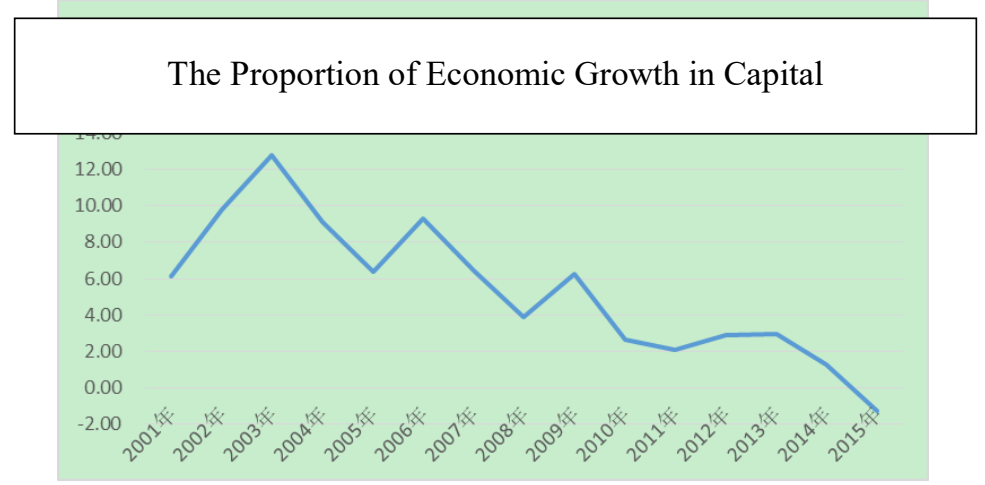

Fig. 2 the Proportion of Economic Growth in Capital

What forms great contrast to that is the elasticity of the economic contribution of the labor force? The negative elasticity of labor force before 2008 shows that the contribution of labor force to economic growth is not obvious, which mainly results from the three reasons: (1) the quality of Chinese labor is low; (2) there is a large number of surplus labor force in China before 2008, and the surplus labor force is in a recessive unemployment state, namely, although they are counted in the category of employment, their contribution to economic growth is quite small. A law is also worth noting, however, there is a recovery in the economic contribution rate of our country's labor year after year before 2008. After 2008, it transferred from negative to positive, which shows that, on the one hand, with the development of economy in our country, the quality of the labor force is being improved constantly. On the other hand, it suggests an increasing marginal return of labor, and that the demographic dividend in China is gradually disappearing.

The Economic Contribution Rate of Labor

Force

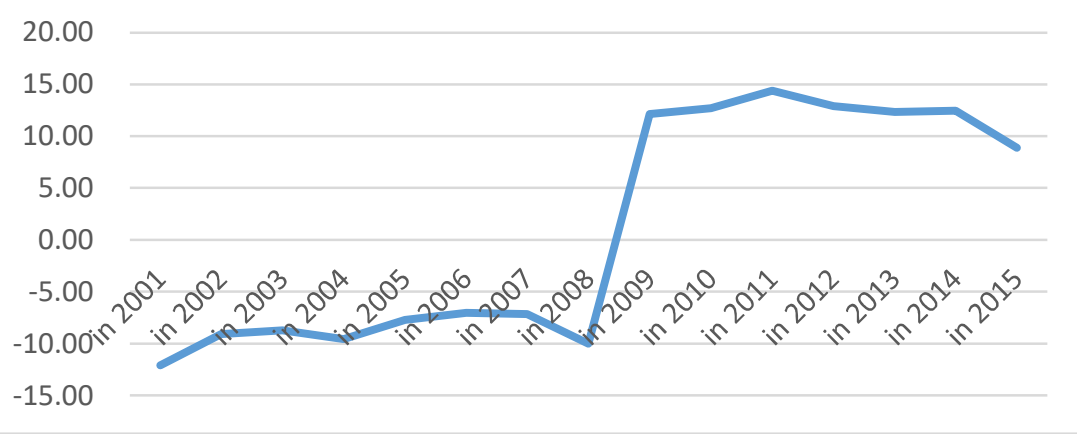

Fig. 3 the Economic Contribution Rate of Labor Force 
Then it comes to total factor productivity. Total factor productivity represents, to some extent, the contribution of technological development to economic growth. As can be seen from table 1, before 2008, China's total factor productivity maintained a relatively high standard. It is well known that the driving force of China's economy since China's reform and opening up is mainly the capital accumulation and cheap labor. After 2000, the improvement of China's total factor productivity indicates that the contribution of China's scientific and technological development to economic development is gradually increasing. After 2008, the total factor productivity turned into negative value. Since the economic contribution of the development of science and technology would not be negative, it can be concluded that the proportion of the contribution of the development of science and technology to the economic development relatively shrank after 2008. To some extent, it is attributed to that China's economy did not transit timely, and the technological content lagged behind the current economic development rhythm. Seen from the following table, in recent years, as the central government has repeatedly stressed economic transition and economic restructuring, the total factor productivity has rebounded.

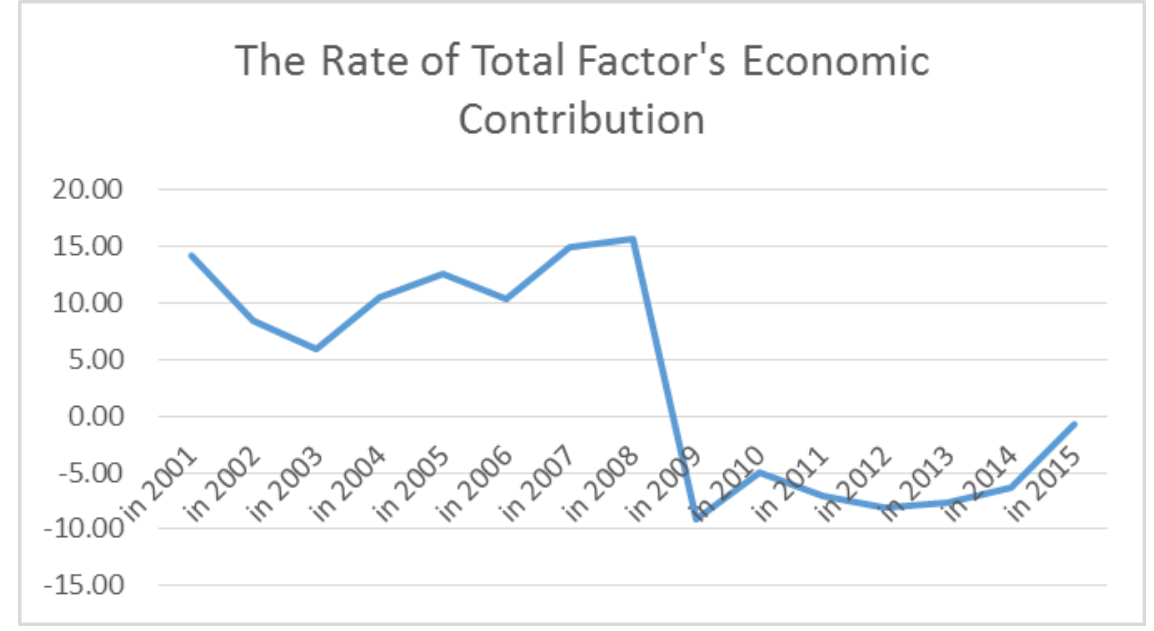

Fig. 4 the Rate of Total Factor's Economic Contribution

\section{Conclusion}

From the above analysis, it is not difficult to conclude the causes of China's economic downturn after 2008. In 2008, China experienced the financial crisis, and the strong fiscal stimulus policies overemphasized the investment on infrastructure, which resulted in a rapid decline in the marginal returns of capital accumulation. At the same time, China's demographic dividend has gradually disappeared, which further aggravates the difficulties of the development of China's economy.The decline of total factor productivity indicates that China's overall scientific and technological content has not been improved along with the economic development, which as a result cannot meet the requirements of current economic development. Although in recent years the central government constantly stressed the importance of the economic transformation and the upgrade of economic structure, the capital accumulation and cheap labor is no longer enough to support China's rapid economic development. It will still take time to achieve economic transformation by relying on high technology to promote the development of economy.

\section{References}

[1]. Arrow, K. J. and L. Hurwitz, Competitive Stability under Weak Gross Substitutability: Nonlinear Price Adjustment and Adaptive Expectations, International Economic Review 3(2): 233-255, 1962.

[2]. Becker, G. S. and K. M. Murphy, the Division of Labour, Coordination Costs, and Knowledge, Quarterly Journal of Economics, 107(4): 1137-1160, 1992. 
[3]. Domtar, E. D, The problem of capital accumulation, The American Economic Review 38(5): 777-794, 1948.

[4]. Easterly, W. and R. Levine, What have we learned from a decade of empirical research on growth? It's Not Factor Accumulation: Stylized Facts and Growth Models, the World Bank Economic Review, 15(2): 177-219, 2001.

[5]. Harrods, R, an Essay in Dynamic Theory, Economic Journal, 49(193): 14-33, 1939.

[6]. Lucas Jar, R. E, on the mechanics of economic development, Journal of monetary economics, 22(1): 3-42, 1988.

[7]. Prescott, E. C, Lawrence R. Klein lecture 1997: Needed: A theory of total factor productivity, International Economic Review: 525-551, 1998.

[8]. Roomer, P. M, Increasing Returns and Long-Run Growth, Journal of Political Economy, 94(5): 1002-1037, 1986.

[9]. Roomer, P. M, Human capital and growth: Theory and evidence, 1990.

[10]. Schultz, T. W, and Investment in human capital: reply, The American Economic Review, 51(5): 1035-1039, 1961.

[11]. Solow, R. M, Technical change and the aggregate production function, the review of Economics and Statistics, 312-320, 1957.

[12]. Yang, X. and J. Borland, a Microeconomic Mechanism for Economic Growth, Journal of Political Economy, 99(3): 460-482, 1991.

[13]. Young, A. A, Increasing Returns and Economic Progress, Economic Journal, 38(152): $527-542,1928$.

[14]. Rostov, Stage of Economic Growth, the Commercial Press, 1962.

[15]. Adam Smith, the Wealth of Nations (Chinese Version), Central Compilation \& Translation Press, 2013. 